\title{
Effects of a Sustained Insulin Infusion Upon Glucose Uptake and Oxygenation of the Ovine Fetus
}

\author{
BONITA S. CARSON ${ }^{(24)}$, ANTHONY F. PHILIPPS, MICHAEL A. SIMMONS ${ }^{(23)}$, \\ FREDERICK C. BATTAGLIA, AND GIACOMO MESCHIA \\ Division of Perinatal Medicine, Departments of Pediatrics, Physiology and Obstetrics-Gynecology, University of \\ Colorado Medical Center, Denver, Colorado, USA
}

\section{Summary}

The effect of insulin upon fetal metabolism is an important question to resolve, bearing in mind that the metabolic effects of insulin on the fetus could differ both quantitatively and qualitatively depending upon the degree and duration of the hyperinsulinemia. The present study was designed to determine whether the effect of fetal hyperinsulinemia on umbilical glucose uptake could be sustained over several days of infusion with various levels of insulin. An unexpected outcome of the study was the observation that this procedure was accompanied by the development of fetal hypoxia.

Fetal glucose/oxygen quotients $\left(\mathrm{G} / \mathrm{O}_{2}\right)$ increased during fetal insulin infusions from a mean of 0.48 during the control period to 0.71 when fetal insulin levels were less than 80 micro units $/ \mathbf{m l}(P$ $<0.01$ ) and to 0.85 when fetal insulin levels were greater than 200 micro units $/ \mathrm{ml}(P<0.001)$. The increase in $\mathrm{G} / \mathrm{O}_{2}$ occurred within $4 \mathrm{hr}$ of infusion in all cases $(P<0.005)$ and was sustained for the duration of the infusions.

The increase in $\mathrm{G} / \mathrm{O}_{2}$ was due to a significant rise in the arteriovenous differences of whole blood glucose across the umbilical circulation $(P<0.001)$. Oxygen content differences across the umbilical circulation also increased during infusion $(P<0.005)$. This was due primarily to a significant and progressive decline in the fetal arterial oxygen content $(P<0.001)$. By $24 \mathrm{hr}$ after the insulin had been stopped, the oxygen content rose and returned to pre-infusion values by the 3 rd day of recovery.

Fetal plasma glucose concentration fell during insulin infusion $(P<0.001)$ and rebounded sharply to levels significantly higher than control values $(P<0.001)$ within $4 \mathrm{hr}$ after the infusion was stopped. The plasma glucose returned to control values by the 3 rd day of recovery.

Insulin levels ranged from 0-16 micro units/ml during control periods and from 48-1166 micro units/ml during infusion. There was a significant positive correlation between the $\mathrm{G} / \mathrm{O}_{2}$ quotient and the log of fetal insulin concentration. There was a negative correlation between the fetal arterial oxygen content and insulin concentration.

Five twin pairs were studied in which one twin served as control and the other as the infusion subject. The values of glucose, G/ $\mathrm{O}_{2}$, and arteriovenous differences of glucose and oxygen were significantly different between the infused and control twin fetuses within $4 \mathrm{hr}$ of infusion and the oxygen content was significantly lower in the infused twin by $24 \mathrm{hr}$ of infusion. There were no significant differences in these measurements between the twins before infusion.

\section{Speculation}

Insulin infusions of several days duration into the fetal lamb cause a sustained increase in umbilical glucose uptake and a decrease in fetal arterial oxygen content. The progressive decline in fetal arterial oxygen content during infusion may be due to an increase in fetal oxygen consumption. The effect of insulin upon fetal oxygenation may be one of the pathophysiologic factors contributing to the increased intrauterine death rate of infants of diabetic mothers.

Macrosomia and increased perinatal mortality are characteristic of fetuses of diabetic pregnancies which, in turn, have been associated with maternal hyperglycemia and fetal hyperinsulinemia $(7-9,11,19)$. Insulin secretion by the fetal pancreas is increased by hyperglycemic stimuli $(1,6,11,12)$. However, the exact metabolic roles of insulin in fetal life are controversial $(3-5,13$, $14,16)$. The effect of insulin upon fetal metabolism is an important question to resolve, bearing in mind that the metabolic effects of insulin on the fetus could differ both quantitatively and qualitatively depending upon the degree and duration of the hyperinsulinemia.

Previous experiments in this laboratory have shown that over a 4-hr period fetal insulin administration results in a $50 \%$ increase in glucose uptake via the umbilical circulation, without changes in fetal oxygen consumption (16). The present study was designed to determine whether the effect of fetal hyperinsulinemia on umbilical glucose uptake could be sustained over several days of infusion with various levels of insulin. An unexpected outcome of the study was the observation that this procedure was accompanied by the development of fetal hypoxia.

\section{MATERIALS AND METHODS}

Nine Western breed ewes with fetuses of 80-130 days of gestation (four with singleton pregnancies and five with twin pregnancies) were prepared for chronic studies by placing polyvinyl catheters in the umbilical vein (" $\gamma$ "), fetal pedal or femoral artery (" $\alpha$ "), fetal pedal vein, and in a maternal femoral artery. The umbilical venous catheter was inserted at the base of the cord and advanced into the common umbilical vein according to a technique previously described (15). The animals were allowed to recover from the operative stress for a minimum of four days before beginning the control period.

Each animal was studied during a steady-state control period, and then again during a chronic insulin infusion. A total of 12 fetal infusions were carried out after stable fetal and maternal concentrations of glucose and oxygen content had been demonstrated over at least 2 consecutive days. All infused fetuses served as their own controls and, in six experiments, the uninfused twin fetus provided an additional control.

Fetal hyperinsulinemia was induced after the control period with procine crystalline zinc insulin (Eli Lilly and $\mathrm{Co}$.) diluted in normal saline. A priming dose of $0.1 \mathrm{unit} / \mathrm{kg}$ of insulin was given, followed by a constant infusion calculated to produce fetal concentrations ranging from $50-1000$ micro units $/ \mathrm{ml}$ with infusion 
rates of $1 \mathrm{ml}$ or less per $\mathrm{hr}$. The insulin infusion was continued for 2-4 days. In three experiments, studies were discontinued when the infusion ended because of either catheter failure or spontaneous delivery. No measurements were performed during labor. In the remaining nine experiments, the authors were able to continue the studies through a recovery period after the infusion was stopped. One animal went through the protocol twice, with sampling periods during control, insulin infusion, recovery during reestablishment of a stable control period, and then again during a repeated insulin infusion and recovery period. In the remaining three twin pairs, only one fetus was infused with insulin.

During all study periods (control, infusion, and recovery) whole blood samples were obtained simultaneously from the umbilical vein and fetal artery an average of three times daily. The study was initiated after the ewe had recovered from surgery and her plasma glucose was greater than $55 \mathrm{mg} / \mathrm{dl}$. Whole blood glucose concentration, oxygen content, $\mathrm{pH}$, and hematocrit were measured as well as plasma concentrations of glucose and insulin. Because some of the infusions were continued over the weekend when the full complement of technical staff was not available, some study days included only measurement of fetal arterial $\mathrm{O}_{2}$ content, hematocrit, plasma glucose, and insulin. On such days and in the two instances in which the umbilical vein catheter failed, measurements of whole blood glucose and oxygen content across the umbilical circulation could not be made.

Oxygen contents were determined with a Lex- $\mathrm{O}_{2}$-Con (Lexington Instrument Corp.) calibrated with distilled water saturated with oxygen at $0^{\circ} \mathrm{C}$. Glucose concentration was measured on both whole blood and plasma by glucose oxidase methods $(17,18)$. Radioimmunoassay for insulin was performed utilizing a modification of the double antibody separation method of Morgan and Lazarow (10) and Philipps et al (12).

The paired Student's $t$ test was used to assess the significance of differences between daily means for each animal. Linear regression analysis was used to analyze the relationships between variables.

Whenever whole blood glucose and $\mathrm{O}_{2}$ content could be measured across the umbilical circulation, umbilical $\mathrm{G} / \mathrm{O}_{2}$ were calculated as previously described (20) according to the following formula:

$$
\mathrm{G} / \mathrm{O}_{2}=\frac{6 \times \Delta \text { glucose }}{\Delta \mathrm{O}_{2}}
$$

where $\Delta$ glucose and $\Delta \mathrm{O}_{2}$ represent the venoarterial differences of whole blood glucose and oxygen, respectively. At a stable oxygen consumption, changes in $\mathrm{G} / \mathrm{O}_{2}$ reflect variations in fetal glucose uptake (20).

\section{RESULTS}

Fetal glucose/oxygen quotients increased during fetal insulin infusions from a mean of 0.48 during the control period to 0.71 when fetal insulin levels were less than 80 micro units $/ \mathrm{ml}(P<$ $0.01)$ and to 0.85 when fetal insulin levels were greater than 200 micro units $/ \mathrm{ml}(P<0.001)$. The increase in $\mathrm{G} / \mathrm{O}_{2}$ occurred within $4 \mathrm{hr}$ of infusion in all cases $(P<0.005)$ and was sustained for the duration of the infusions (Fig. 1).

The increase in $\mathrm{G} / \mathrm{O}_{2}$ was due to a significant rise in the arteriovenous differences of whole blood glucose across the umbilical circulation $(P<0.001)$. Oxygen content differences across the umbilical circulation also increased during infusion $(P<$ 0.005 ) as exemplified by the experiment depicted in Figure 3. This was due primarily to a significant and progressive decline in the fetal arterial oxygen content $(P<0.001)$ (Fig. 2A). Within $24 \mathrm{hr}$ after the insulin infusion was begun, the oxygen content began to fall and continued to fall for the duration of the infusion; by $24 \mathrm{hr}$ after the insulin had been stopped, the oxygen content rose and returned to preinfusion values by the 3 rd day of recovery. The fetal $\mathrm{pH}$ during both control and infusion periods was $7.33 \pm$ SEM 0.009 .

Data from the animal which received an insulin infusion on two

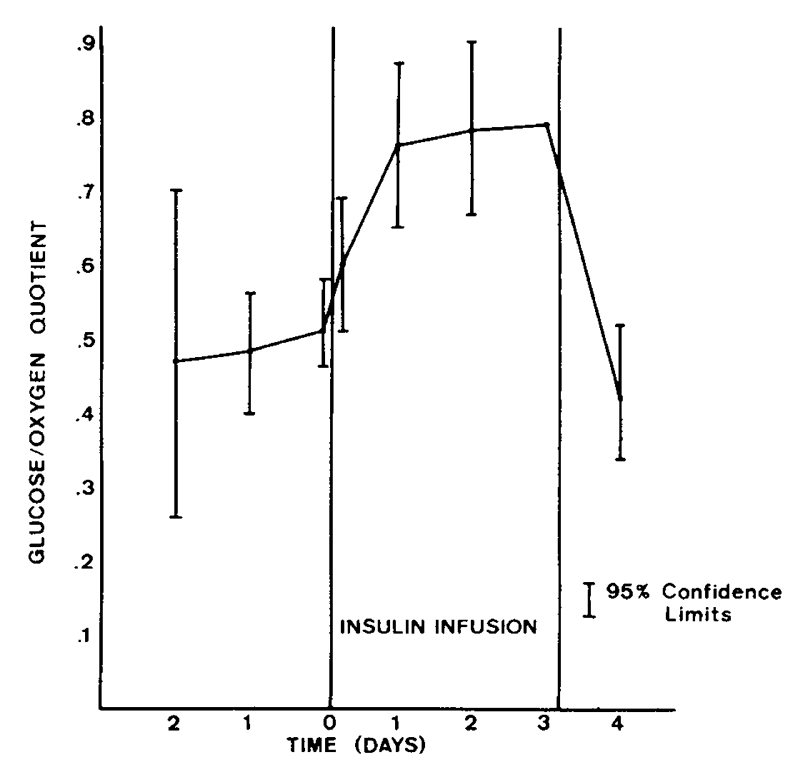

Fig. 1. Fetal $\mathrm{G} / \mathrm{O}_{2}$ quotients before, during, and after fetal insulin infusion (mean $\pm 95 \%$ confidence limits).

separate occasions are illustrated in Figure 3. Each point represents the mean of three or more samples obtained daily. Insulin led to reproducible changes in $\mathrm{G} / \mathrm{O}_{2}$, whole blood glucose and oxygen content differences during these separate infusions. Figure 4 presents data obtained from a twin pair in which the fetuses were alternately infused. Changes in fetal arterial oxygen content during infusion and recovery occurred in both twins.

Fetal plasma glucose concentration fell during insulin infusion $(P<0.001)$ and rebounded sharply to levels significantly higher than control values $(P<0.001)$ within $4 \mathrm{hr}$ after the infusion was stopped. The plasma glucose returned to control values by the $3 \mathrm{rd}$ day of recovery (Fig. 2B).

Nine animals were studied after the fetal insulin infusion was stopped. In all animals the $\mathrm{G} / \mathrm{O}_{2}$ quotient fell $(P<0.005)$, the arteriovenous differences in glucose $(P<0.001)$ and oxygen $(P$ $<0.05)$ fell, and the arterial oxygen content rose $(P<0.005)$ when recovery values were compared to infusion values.

Insulin levels ranged from $0-16$ micro units $/ \mathrm{ml}$ during control periods and from 48-1166 micro units/ml during infusion. In general, the $\mathrm{G} / \mathrm{O}_{2}$ was increased and the oxygen content was lower the higher the plasma insulin concentration. There was a significant positive correlation between the $\mathrm{G} / \mathrm{O}_{2}$ quotient and the $\log$ of fetal insulin concentration (Fig. 5A). There was a negative correlation between fetal arterial oxygen content and insulin concentration (Fig. 5B).

Five twin pairs were studied in which one twin served as control and the other as the infusion subject. In one of these pairs, the twins were alternately infused. The values of glucose, $\mathrm{G} / \mathrm{O}_{2}$, and arterio-venous differences of glucose and oxygen were significantly different between the infused and control twin fetuses within $4 \mathrm{hr}$ of infusion and the oxygen content was significantly lower in the infused twin by $24 \mathrm{hr}$ of infusion. There were no significant differences in these measurements between the twins before infusion (Table 1).

In the current study, glucose uptake was assessed by measuring whole blood glucose and the oxygen content simultaneously in the umbilical vein and fetal artery and then calculating a ratio which is referred to as the $\mathrm{G} / \mathrm{O}_{2}(20)$. This ratio represents glucose uptake per millimole of oxygen consumed by the fetus. To affirm that variability of the $\mathrm{G} / \mathrm{O}_{2}$ reflects primarily variability of glucose uptake, the authors calculated $\mathrm{G} / \mathrm{O}_{2}$ from whole blood glucose and oxygen content data collected during a previous study (16) in this laboratory, and in subsequent unpublished observations, in which umbilical blood flow had been measured and glucose uptake calculated according to the Fick principle. Measurements 


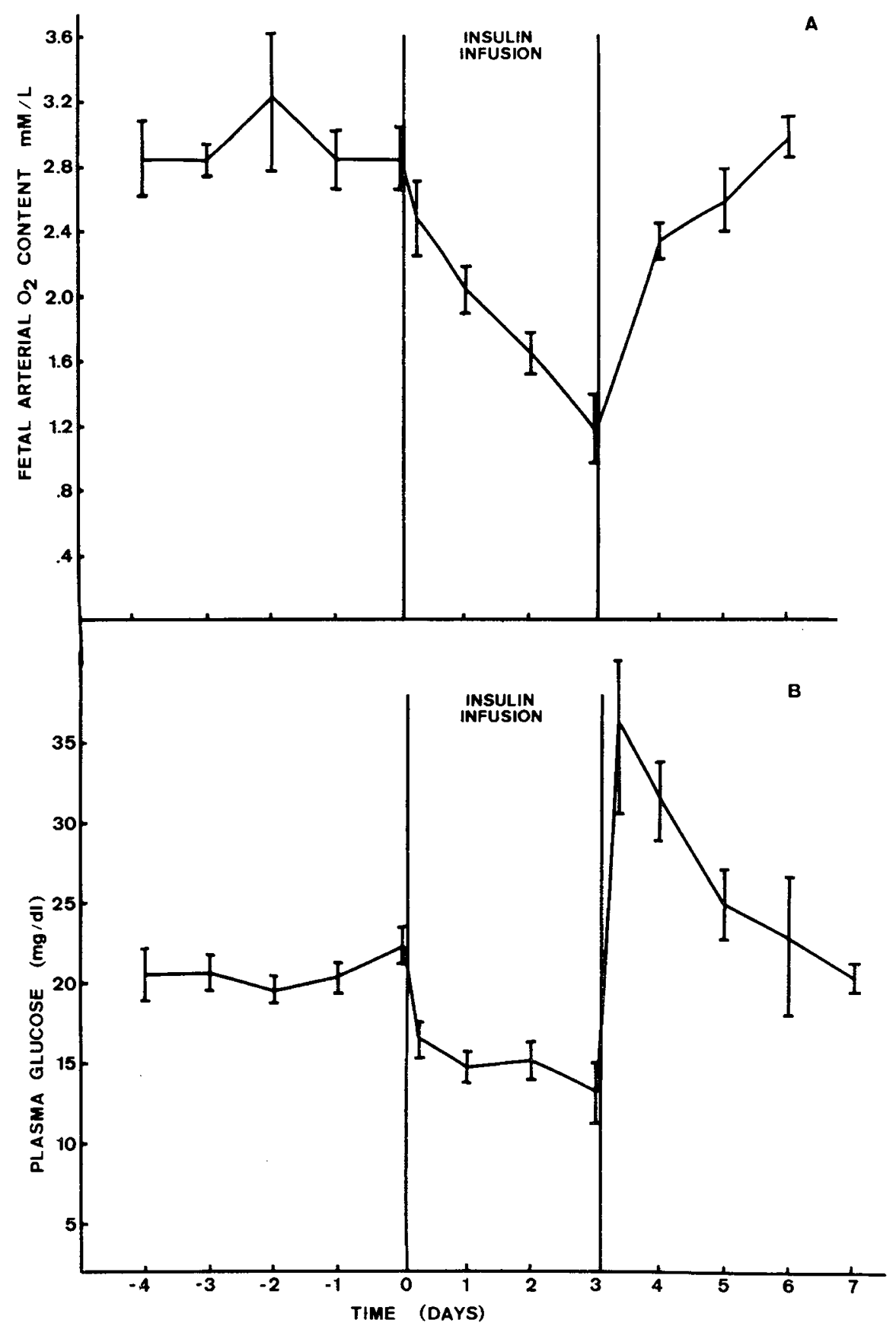

Fig. 2. Fetal arterial oxygen content $(A)$ and fetal plasma glucose $(B)$ before, during, and after insulin infusion (mean \pm SEM).

Table 1. Effect of insulin on infused vs. control twin. Mean fetal plasma glucose, umbilical venoarterial differences $(\gamma-a)$ in whole blood glucose and oxygen, the umbilical $\mathrm{G} / \mathrm{O}_{2}$ quotient, and the arterial oxygen content in control $(C)$ and experimental $(E)$ twins are presented. The $P$ values were derived by paired t test comparison of $C$ and $E$.

\begin{tabular}{|c|c|c|c|c|c|c|c|c|c|}
\hline \multirow[b]{2}{*}{$\begin{array}{l}\text { Plasma glucose } \\
\text { (mg/dl) }\end{array}$} & \multirow[b]{2}{*}{$\begin{array}{l}\mathrm{C} \\
\mathrm{E}\end{array}$} & \multicolumn{2}{|c|}{$24 \mathrm{hr}$ before infusion } & \multicolumn{2}{|c|}{$4 \mathrm{hr}$ of infusion } & \multicolumn{2}{|c|}{$24 \mathrm{hr}$ of infusion } & \multicolumn{2}{|c|}{$48 \mathrm{hr}$ of infusion } \\
\hline & & $\begin{array}{l}21.02 \\
21.16\end{array}$ & N.S. & $\begin{array}{l}21.78 \\
15.77\end{array}$ & $P<0.025$ & $\begin{array}{l}20.95 \\
12.76\end{array}$ & $P<0.005$ & $\begin{array}{l}21.03 \\
13.65\end{array}$ & $P<0.05$ \\
\hline $\begin{array}{l}(\gamma-a) \text { Blood glucose } \\
(\mathrm{mM})\end{array}$ & $\begin{array}{l}\mathrm{C} \\
\mathrm{E}\end{array}$ & $\begin{array}{l}0.126 \\
0.138\end{array}$ & N.S. & $\begin{array}{l}0.111 \\
0.185\end{array}$ & $P<0.05$ & $\begin{array}{l}0.128 \\
0.235\end{array}$ & $P<0.025$ & $\begin{array}{l}0.133 \\
0.232\end{array}$ & $P<0.001$ \\
\hline $\begin{array}{l}(\gamma-a) \text { Oxygen content } \\
\quad(\mathrm{mM})\end{array}$ & $\begin{array}{l}\mathrm{C} \\
\mathrm{E}\end{array}$ & $\begin{array}{l}1.56 \\
1.65\end{array}$ & N.S. & $\begin{array}{l}1.55 \\
1.75\end{array}$ & $P<0.025$ & $\begin{array}{l}1.43 \\
1.98\end{array}$ & $P<0.005$ & $\begin{array}{l}1.62 \\
2.08\end{array}$ & $P<0.01$ \\
\hline $\mathrm{G} / \mathrm{O}_{2}$ quotient & $\begin{array}{l}\mathrm{C} \\
\mathrm{E}\end{array}$ & $\begin{array}{l}0.46 \\
0.46\end{array}$ & N.S. & $\begin{array}{l}0.44 \\
0.62\end{array}$ & $P<0.05$ & $\begin{array}{l}0.53 \\
0.68\end{array}$ & $P<0.05$ & $\begin{array}{l}0.50 \\
0.68\end{array}$ & $P<0.005$ \\
\hline $\begin{array}{l}\text { Oxygen content } \\
\text { (mM) }\end{array}$ & $\begin{array}{l}\mathrm{C} \\
\mathrm{E}\end{array}$ & $\begin{array}{l}2.80 \\
2.83\end{array}$ & N.S. & $\begin{array}{l}2.60 \\
2.53 \\
\end{array}$ & N.S. & $\begin{array}{l}2.72 \\
1.90 \\
\end{array}$ & $P<0.01$ & $\begin{array}{l}2.84 \\
1.18 \\
\end{array}$ & $P<0.01$ \\
\hline
\end{tabular}


150

CARSON ET AL.

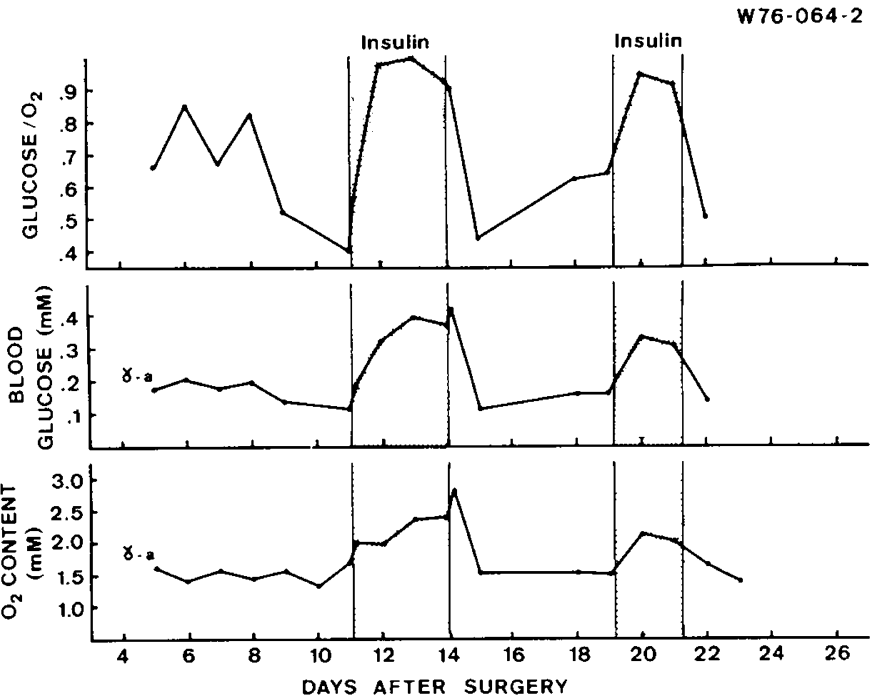

Fig. 3. Fetal $\mathrm{G} / \mathrm{O}_{2}$ quotient, umbilical arteriovenous difference in whole blood glucose and umbilical arteriovenous difference in oxygen content in a fetus receiving insulin infusion on two occasions.

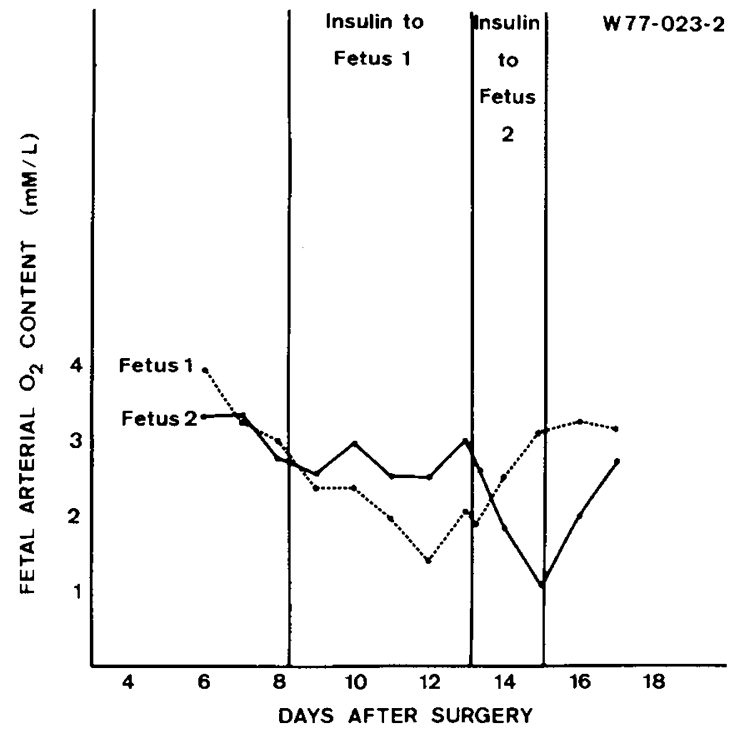

Fig. 4. Fetal arterial oxygen content in twins alternately infused with insulin.

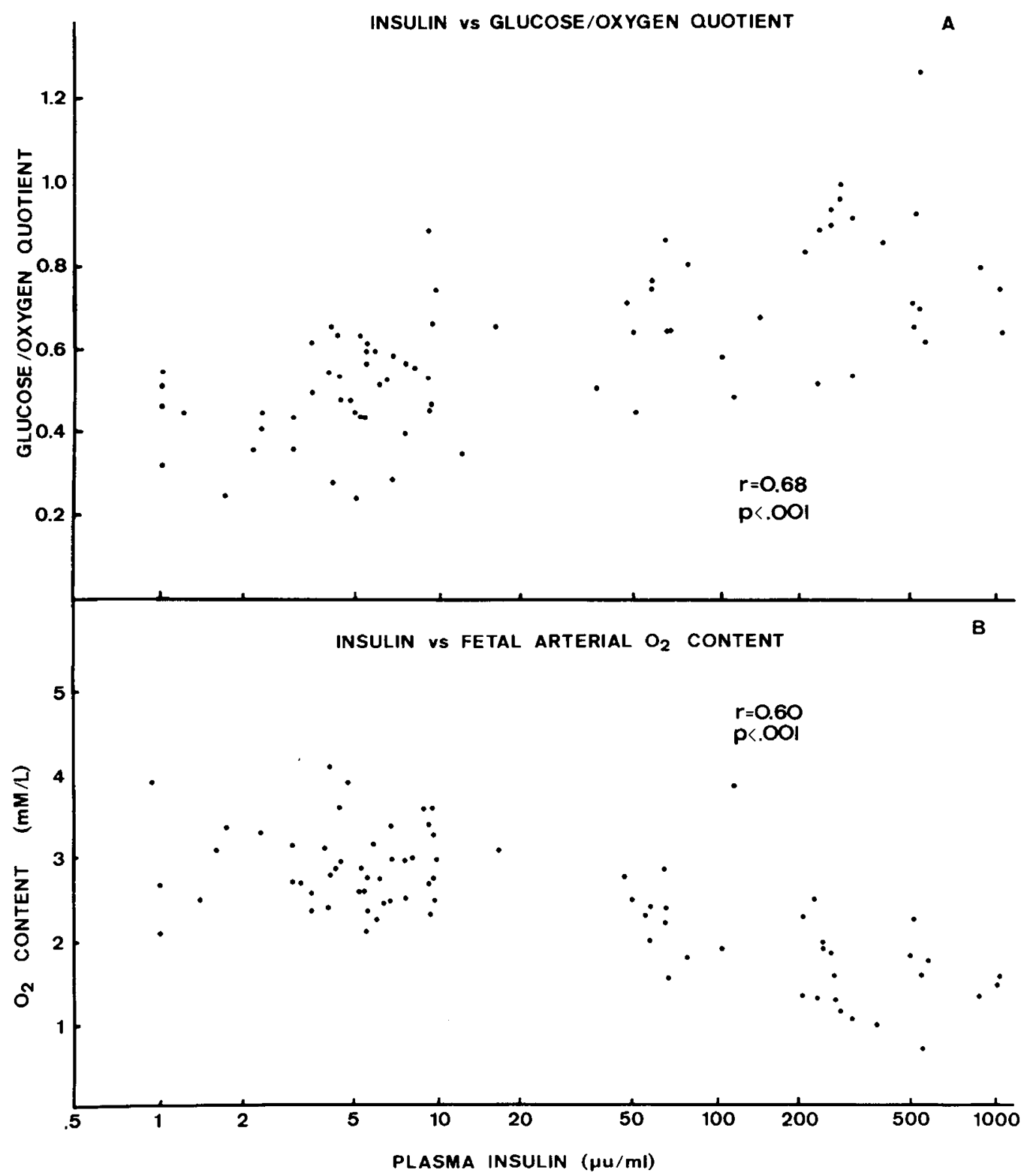

Fig. 5. Fetal $\mathrm{G} / \mathrm{O}_{2}$ quotient $(A)$ and fetal arterial oxygen content $(B)$ with varying fetal plasma insulin concentration. 
in these studies had been made during the normal fed state, maternal fasting, fetal insulin infusions, and maternal glucose infusions. The relationship between the $\mathrm{G} / \mathrm{O}_{2}$ and glucose uptake was linear with a correlation coefficient of 0.95 (Fig. 6).

\section{DISCUSSION}

The increase in $\mathrm{G} / \mathrm{O}_{2}$ during hyperinsulinemia is dose-related (Fig. 5A). After cessation of the insulin infusion both the $\mathrm{G} / \mathrm{O}_{2}$ quotient (Fig. 1) and the fetal plasma glucose return to normal. However, the fetus demonstrated rebound hyperglycemia shortly after the infusion is stopped (Fig. 2B) suggesting a brief period of decreased fetal glucose utilization. The rebound in fetal glucose concentration which occurs during this recovery period needs further study.

Normally, ovine twin fetuses have separate circulations. During insulin infusion in one twin, the insulin levels in the control twin were normal. Thus, the distinct separation of glucose responses in the two twins is not surprising. Utilizing such a preparation further substantiates the direct effect of insulin on fetal glucose uptake, because the maternal glucose concentration was identical for both twins. The crossover experiment in the twins also confirms that the difference in glucose uptake during insulin infusion is not dependent on host or environmental factors.

The authors can now compare umbilical $\mathrm{G} / \mathrm{O}_{2}$ quotients during fetal hypoglycemia produced in two different ways. Figure 7 presents the $\mathrm{G} / \mathrm{O}_{2}$ quotient plotted against fetal plasma glucose concentration during control, insulin infusion, and starvation periods. The data include those from the present study as well as from previous studies in this laboratory $(15,16)$. Fetal glucose concentrations during starvation and insulin infusion were similar, but the $\mathrm{G} / \mathrm{O}_{2}$ quotients (and, thus, presumably glucose uptakes) were low during starvation and high during insulin infusion. Bassett and Madill (2) and Philipps et al. (12) have shown that fetal as well as maternal insulin levels during starvation are decreased. It may be concluded from this information that the rate of exogenous glucose utilization by the fetal organism is insulin dependent and not directly controlled by fetal glucose concentration.

A surprising finding in this study was the progressive decline in fetal arterial oxygen content during insulin infusion. This phenomenon appears to be related to both the insulin concentration and the duration of the infusion (Figs. 2B and 5B). After the infusion was stopped, fetal arterial oxygen content returned to normal

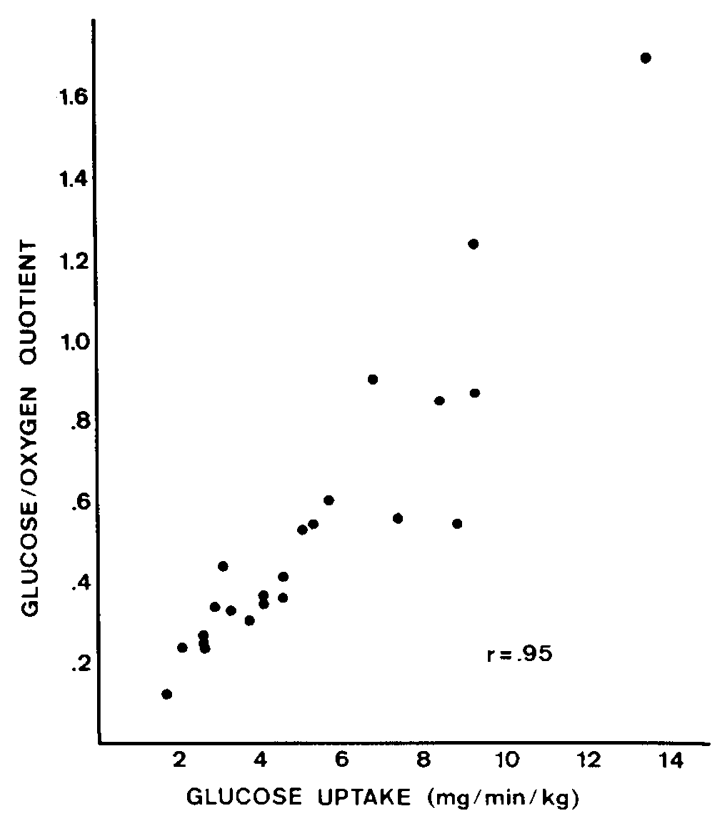

Fig. 6. Relationship between fetal $\mathrm{G} / \mathrm{O}_{2}$ quotient and fetal glucose uptake.

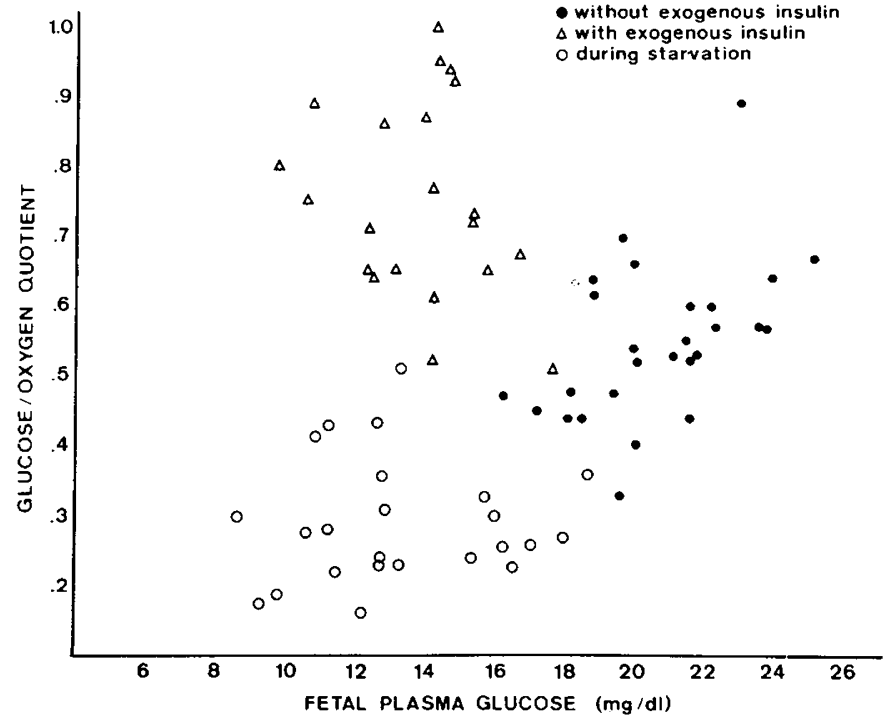

Fig. 7. Fetal $\mathrm{G} / \mathrm{O}_{2}$ quotient at varying fetal arterial plasma glucose concentrations during the control fed state, with exogenous insulin and during starvation.

within $48 \mathrm{hr}$. Fetal hypoglycemia induced by maternal fasting is not associated with a decrease in fetal arterial oxygen content (15). Thus, the fall in arterial oxygen content appears to be related to the fetal hyperinsulinemia, not to hypoglycemia.

The fall in fetal arterial oxygen content could be due to an increased fetal and/or placental oxygen consumption or to a decrease in umbilical blood flow. An effect of hyperinsulinemia on myocardial function in infants of diabetic mothers has been reported (21). Impairment of myocardial function would lead to a decrease in umbilical blood flow, which if progressive, might result in fetal demise. However, an effect of insulin on fetal oxygen consumption is a plausible alternative explanation. Regardless of the mechanism, the present study demonstrates that fetal hyperinsulinemia may have a profound effect upon fetal oxygenation. The nature of this effect needs further investigation.

\section{REFERENCES AND NOTES}

1. Bassett, J. M., and Madill, D.: Influence of prolonged glucose infusions on plasma insulin and growth hormone concentrations of foetal lambs. J. Endocr. 62: 299 (1974).

2. Bassett, J. M., and Madill, D.: The influence of maternal nutrition on plasma hormone and metabolite concentrations of foetal lambs. J. Endocr., 61: 465 (1974).

3. Bocek, R. M., and Beatty, C. H.: Effect of insulin on the carbohydrate metabolism of the fetal rhesus monkey muscle. Endocrinology, 85: 615 (1969).

4. Chez, R. A., Mintz, D. H., Horger, E. O., and Hutchinson, D. L.: Factors affecting the response to insulin in the normal subhuman pregnant primate. J. Clin. Invest., 49: 1517 (1970).

5. Clark, C. M., Cahill, G. F., and Soeldner, J. S.: Effects of exogenous insulin on the rate of fatty acid synthesis and glucose C-14 utilization in the 20-day rat fetus. Diabetes, 17: 362 (1968).

6. Davis, J. F., Beck, P., Colwill, J. R., Makowski, E. L., Meschia, G., and Battaglia, F. C.: Insulin response to fructose and glucose infusions into the sheep fetus. Proc. Soc. Exp. Biol. Med., 136: 972 (1971).

7. Driscoll, S. G.: The pathology of pregnancy complicated by diabetes mellitus. The Medical Clinics of North America, Vol. 49. pp. 1053-1067 (W. B. Saunders Company, Philadelphia, 1965).

8. Francois, R., Picaud, J. J., Ruitton-Ugliengo, A., David, L., Cartal, M. J., and Bauer, D.: The newborn of diabetic mothers. Biol. Neonate. 24: 1 (1974).

9. Kitzmiller, J. L., Cloherty, J. P., Younger, M. D., Tabatabaii, A., Rothchild, S. B., Sosenko, I., Epstein, M. F., Singh, S., and Neff, R. K.: Diabetic pregnancy and perinatal morbidity. Amer. J. Obstet. Gynecol., 131: 560 (1978).

10. Morgan, C. R., and Lazarow, A.: Immunoassay of insulin: two antibody system. Diabetes, 12: 115 (1963)

11. Obenshain, S. S., Adam, P. A. J., King, K. C., Teramo, K., Raivio, K. O., Räihä, N., and Schwartz, R.: Human fetal insulin response to sustained maternal hyperglycemia. N. Engl. J. Med., 283: 566 (1970).

12. Philipps, A. F., Carson, B. S., Meschia, G., and Battaglia, F. C.: Insulin secretion in fetal and newborn sheep. Amer. J. Physiol. 235: E467 (1978)

13. Picon, L.: Effect of insulin on growth and biochemical composition of the rat 
fetus. Endocrinology, 81: 1419 (1967).

14. Rabain. F., and Picon. L.: Effect of insulin on the materno-fetal transfer of glucose in the rat. Horm. Metab. Res., 6: 376 (1974).

15. Schreiner, R. L.. Burd, L. I., Jones, M. D., Lemons, J. A., Sheldon, R. E. Simmons, M. A., Battaglia, F. C., and Meschia, G.: Fetal Metabolism in Fasting Sheep. In: L. Longo: Circulation of the Fetus and Newborn. Vol. II. (New York, Garland Press, 1978), pp. 197-222.

16. Simmons. M. A.. Jones, M. D.. Battaglia, F. C., and Meschia, G.: Insulin effect on fetal glucose utilization. Pediatr. Res., 12: 90 (1978).

17. Simmons. M. A.. Meschia, G.. Makowski, E. L., and Battaglia, F. C.: Feta metabolic response to maternal starvation. Pediatr. Res., 8: 830 (1974).

18. Sols, A., and de la Fuente, G.: Hexokinase and other enzymes of sugar metabolism in the intestine. In: J. H. Quastel: Methods in Medical Research Vol. 9, (Chicago, Year Book Publishers, 1961) pp. 302-309.

19. Steinke. J., and Driscoll. S. G.: The extractable insulin content of pancreas from fetuses and infants of diabetic and control mothers. Diabetes. 14: 573 (1965).

Copyright $\odot 1980$ International Pediatric Research Foundation, Inc. $0031-3998 / 80 / 1402-0147 \$ 02.00 / 0$
20. Tsoulos, N. G., Colwill, J. R., Battaglia, F. C., Makowski, E. L., and Meschia, G.: Comparison of glucose, fructose, and $\mathrm{O}_{2}$ uptakes by fetuses of fed and starved ewes. Amer. J. Physiol., 221: 234 (1971).

21. Wolfe, R. R., and Way, G. L.: Cardiomyopathies in infants of diabetic mothers. Johns Hopkins Med. J., 140: 177 (1977).

22. This research was supported by funds from National Institutes of Health Training grant HD 00429, Program grant HD 00781 and Project grant HD 01866 of the National Institutes of Child Health and Human Development and also from a Basil O'Connor Starter Research Grant through the National Foundation of March of Dimes (M. A. S.).

23. Dr. Simmons is an Established Investigator of the American Heart Association. 24. Requests for reprints should be addressed to: Bonita S. Carson, M. D. Division of Perinatal Medicine B-199. University of Colorado Medical Center, 4200 E. 9 th Ave., Denver, Colorado 80262, USA.

25. Received for publication October 31, 1978.

26. Accepted for publication March 14, 1979. 